\title{
Triple therapy (ICS/LABA/LAMA) in COPD: time for a reappraisal
}

This article was published in the following Dove Press journal: International Journal of COPD

\author{
Lowie Vanfleteren ${ }^{1-3}$ \\ Leonardo M Fabbri ${ }^{1,4}$ \\ Alberto $\mathrm{Papi}^{4}$ \\ Stefano Petruzzelli ${ }^{5}$ \\ Bartolome Celli ${ }^{6}$ \\ 'COPD Center, Institute of \\ Medicine, Sahlgrenska University \\ Hospital, University of Gothenburg, \\ Gothenburg, Sweden; ${ }^{2} \mathrm{CIRO}$, Horn, \\ the Netherlands; ${ }^{3}$ Department of \\ Respiratory Medicine, Maastricht \\ University Medical Hospital, \\ Maastricht, the Netherlands; ${ }^{4}$ Section \\ of Cardiorespiratory and Internal \\ Medicine, Department of Medical \\ Sciences, University of Ferrara, \\ Ferrara, Italy; ${ }^{5} \mathrm{Global}$ Clinical \\ Development, Chiesi Farmaceutici \\ SpA, Parma, Italy; ${ }^{6}$ Division of \\ Pulmonary and Critical Care, Brigham \\ and Women's Hospital, Harvard \\ Medical School, Boston, MA, USA
}

Correspondence: Lowie Vanfleteren Sahlgrenska University Hospital, Vita Stråket 12, Plan 0, COPD-centrum, 41345 Gothenburg, Sweden Tel $+4673660 \quad 1730$

Email lowie.vanfleteren@vgregion.se

\begin{abstract}
Recently, two "fixed triple" single-inhaler combinations of an inhaled corticosteroid (ICS), a long-acting $\beta_{2}$-agonist (LABA), and a long-acting muscarinic antagonist (LAMA) have become available for patients with COPD. This review presents the clinical evidence that led to the approval of these triple therapies, discusses the role of ICS in patients with COPD, and presents data on the relative efficacy of "fixed triple" (ICS/LAMA/LABA) therapy vs LAMA, ICS/LABA, and LAMA/LABA combinations, and summarizes studies in which ICS/LABAs were combined with LAMAs to form "open triple" combinations. Of the five main fixed triple studies completed so far, three evaluated the efficacy and safety of an extrafine formulation of beclometasone dipropionate, formoterol fumarate, and glycopyrronium; the other two studies evaluated fluticasone furoate, vilanterol, and umeclidinium. Overall, compared to LAMA, ICS/LABA, or LAMA/LABA, triple therapy decreased the risk of exacerbations and improved lung function and health status, with a favorable benefit-to-harm ratio. Furthermore, triple therapy showed a promising signal in terms of improved survival. The evidence suggests that triple therapy is the most effective treatment in moderate/severe symptomatic patients with COPD at risk of exacerbations, with marginal if any risk of side effects including pneumonia. Ongoing studies are examining the role of triple therapy in less severe symptomatic patients with COPD and asthma-COPD overlap.
\end{abstract}

Keywords: muscarinic antagonists, adrenergic $\beta_{2}$ receptor agonists, glucocorticoids, pulmonary disease, chronic obstructive, review, exacerbations, safety

\section{Introduction}

Current recommendations are that the pharmacological treatment of COPD should take a "personalized" approach, based around the use of either single therapy or a combination of medications with different or complementary mechanisms of action. ${ }^{1}$ The role of inhaled corticosteroids (ICSs) in the maintenance treatment of COPD came under scrutiny, in part following a single study showing the benefit on exacerbation frequency of dual bronchodilation of a long-acting $\beta_{2}$-agonist (LABA) and a long-acting muscarinic antagonist (LAMA), over a LABA plus ICS. ${ }^{2}$ The Global Initiative for Chronic Obstructive Lung Disease (GOLD) suggested that the addition of ICS to dual bronchodilation was to be reserved primarily for patients with symptomatic disease and a history of frequent exacerbations (two or more in the previous year), or one or more exacerbations leading to hospitalization. ${ }^{1}$ However, recent studies in patients with moderate-to-very severe airflow limitation, most of whom had an exacerbation history, show otherwise. Large controlled trials of the two available ICS/LABA/LAMA triple combinations in a single inhaler showed significant benefits not only on exacerbations, but also on lung function, health status, rescue medication use, and importantly, 
potentially the risk of death compared to LAMA monotherapy, ICS/LABA, or LAMA/LABA..$^{3-9}$

This article critically reviews the benefits and safety profile of triple therapy in a single inhaler, and provides expert opinion on its potential role in treatment strategies of patients with COPD.

\section{The historical perspective: bronchodilator use in COPD}

Bronchodilators have occupied a central position in the pharmacological management of COPD, ${ }^{10}$ because the majority of patients respond with variable degrees of bronchodilation to both $\beta_{2}$-agonists and muscarinic receptor antagonists. In addition, all studies comparing bronchodilators with placebo showed improvement in dyspnea, probably related to bronchodilation and/or a decrease in resting lung volume and a delay in dynamic hyperinflation during situations of increased ventilator demands, such as exercise. ${ }^{11}$ The deflationary effect of bronchodilators may even improve cardiac function in patients with increased resting lung volume, providing an interesting mechanism for their benefits. ${ }^{12}$ The advent of tiotropium, a once daily LAMA, modified the landscape, as it was possible to achieve significant increases in trough $\mathrm{FEV}_{1}$ that was evident 24 hours after a single inhalation. This bronchodilator effect was accompanied by significant improvements in health status, dyspnea, and the rate and time to exacerbation. ${ }^{13-15}$

However, there were conflicting reports regarding the long-term safety of inhaled bronchodilators in COPD, primarily related to the intrinsic adrenergic effect of LABAs, and to the suppression of parasympathetic cardiac control with LAMAs. ${ }^{15-22}$ The completion of the 3-year TORCH trial that included a LABA monotherapy arm, and the 4-year UPLIFT trial using tiotropium proved both class of agents to have good overall safety profiles and without any cardiovascular signal. ${ }^{23,24}$ In addition, the larger SUMMIT trial, specifically conducted in patients at increased cardiovascular risk, showed no excess incidence of cardiovascular events or arrhythmias with a LABA compared to placebo. ${ }^{25}$

The cardiovascular risk associated with combined LAMA/LABA bronchodilators has been less studied. A large network meta-analysis, including 23 trials, concluded that LAMA/LABA combination therapy had similar effects on safety outcomes compared with either monotherapy. ${ }^{26}$ In contrast, an increased risk of developing heart failure was reported 1 year after changing from single to dual bronchodilator therapy in a real-world, primary care database, with no increased risk of acute myocardial infarction, stroke, or arrhythmia. ${ }^{27}$ Finally, a meta-analysis comparing dual bronchodilation with monotherapy demonstrated a larger increase in $\mathrm{FEV}_{1}$ with modest difference in health status with LAMA/LABA combination compared with monotherapy, with no increase in cardiovascular risk. ${ }^{28}$ However, the effect of dual bronchodilator over tiotropium alone on exacerbations remains questionable at best. ${ }^{29}$

\section{The historical perspective: ICS use in COPD}

The American Thoracic Society's (ATS) 1986 "Standards for the diagnosis and care of patients with COPD and asthma" suggested that, in asthma, both systemic and inhaled corticosteroids were to be added to bronchodilators only for the treatment and prevention of acute attacks. ${ }^{30}$ In contrast, for patients with COPD, the document recommended systemic steroids only for the treatment of exacerbations, and briefly mentioned the possible use of ICS as maintenance treatment in the few patients who responded, warning against the serious adverse events associated with long-term treatment, mainly since the first ICS, beclometasone dipropionate (BDP), had been studied almost exclusively in asthma. ${ }^{31}$ By the early 2000s, the first edition of the GOLD strategy document and an ATS/European Respiratory Society taskforce were suggesting that ICSs could be added to bronchodilators for patients with severe COPD who are at risk of exacerbations, or in patients with mixed features of COPD and asthma. ${ }^{32,33}$ In fact, the Tucson epidemiology studies had shown that among patients with moderate-to-severe airflow limitation, nonsmokers with asthma and smokers with no history of asthma had very different natural histories, ${ }^{34}$ while the Groningen study showed that the large bronchodilator response to ICS in severely obstructed patients was limited to those with history of asthma. ${ }^{35}$ The rationale for using ICSs alone in asthma was their anti-inflammatory effects, ${ }^{36}$ but it became apparent that the airway and pulmonary inflammation of asthma is quite different from that of COPD. ${ }^{37}$

Four studies completed in the late 1990s investigated whether ICS could ameliorate the progression of COPD, as measured by decline in lung function. ${ }^{38-41}$ In three of the studies, the use of either inhaled budesonide (BUD) or triamcinolone showed no significant difference in rate of lung function decline in the patients randomized to the active medication arm compared with placebo. In contrast, in the ISOLDE study, patients receiving the ICS fluticasone propionate (FLP) had marginally improved lung function decline and better health status than those receiving placebo, with a clear effect on exacerbations, especially in patients with severe airflow limitation. ${ }^{41,42}$ Subsequent studies confirmed the beneficial effect of ICSs on exacerbations, especially when 
given in combination with LABAs. ${ }^{43}$ These results, coupled with a potential signal on mortality derived from retrospective analyses of a general practice database, ${ }^{44}$ and from a metaanalysis of several randomized trials, ${ }^{45}$ prompted a renewed interest in ICS/LABA combinations as potential disease modifiers in COPD. This hypothesis was tested in the large TORCH trial, where the combination of the LABA salmeterol (SAL; $50 \mu \mathrm{g})$ and the ICS FLP $(500 \mu \mathrm{g})$ was compared with placebo and each of the individual components on all-cause mortality over 3 years. ${ }^{23}$ There was a $17 \%$ reduction in the relative risk of death between FLP/SAL and placebo, the difference just missing statistical significance $(P=0.052)$. Since a post hoc analysis of the TORCH data suggested an effect on mortality in patients with cardiovascular disease, the even larger SUMMIT study was conducted in over 16,000 patients with moderate airflow limitation but at heightened cardiovascular risk, demonstrating a $12 \%$ reduction in the relative risk of dying with the combination of fluticasone furoate and vilanterol (FLF/VI) compared with placebo. ${ }^{25}$ This difference was statistically nonsignificant $(P=0.13)$.

However, valuable observations were made in both studies. First, a significant effect of the ICS/LABA was observed on moderate and severe exacerbations even in patients without a history of exacerbations, particularly in those with the most severe degree of airflow limitation. Second, the rates of decline in health status and lung function in both studies were decreased in patients randomized to ICS/LABA. Third, the use of ICS alone in TORCH was associated with an increased risk of death compared with the ICS/LABA combination, prompting the now accepted recommendation of not using ICS monotherapy in COPD. Finally, in TORCH, as in almost all subsequent studies using ICS containing combinations, the incidence of pneumonia was significantly increased in the ICS containing arm, ${ }^{23,46}$ whereas in SUMMIT ${ }^{25}$ and more recent studies, including some of those using triple therapy, the risk of pneumonia was minimal. ${ }^{3,5,47}$ Other documented ICS side effects such as oral candidiasis, hoarseness and potential worsening of diabetes, osteopenia and osteoporosis, or cataract raised some questions and fueled the controversy about the correct positioning of ICS in the treatment of patients with COPD.

\section{Clinical characteristics and markers of potential ICS response}

Guidelines and expert reviews have suggested that the patients with COPD who might benefit the most from the addition of ICS to bronchodilators are those with a history of and/or concomitant asthma, ${ }^{1,48-50}$ consistent with the results of the Groningen study. ${ }^{35}$ Other clinical characteristics have also been associated with potential response to ICS, including a large bronchodilator response, history of allergies and rhinitis. However, the beneficial effect of ICS in this group of patients has never been tested in a formal randomized controlled trial (RCT). Post hoc and prespecified analyses of several RCTs have shown that the effect of ICS/LABAs on exacerbations is related to blood eosinophil counts, with higher blood eosinophil counts consistently predicting a greater effect from ICS/LABA or ICS/LABA/LAMA vs LABA, LAMA, or LAMA/LABA. RCTs comparing triple therapy vs LAMA or LAMA/LABA also confirmed greater effects of triple therapy in patients with higher eosinophil levels $(\geq 150-200$ cells $/ \mu \mathrm{L}){ }^{3,6,51}$ This is in line with a post hoc analysis of the WISDOM study and a prespecified subgroup analysis of the SUNSET study, both of which showed that ICS withdrawal caused increased exacerbations and a greater lung function decline in patients with higher blood eosinophil levels. ${ }^{52,53}$ We acknowledge, however, that the differences in effect between low and high eosinophil levels are numerical and not statistically significant, and that the use of blood eosinophils as a biomarker of increased risk of exacerbations and increased sensitivity to steroids is still highly debated. ${ }^{54}$ Recently published analyses from the GLUCOLD study add to the complexity, since eosinophil counts in any compartment, including blood, were not associated with the response to ICS or longitudinal change in $\mathrm{FEV}_{1}$. In fact, higher biopsy eosinophil counts were associated with an increase in symptoms during 6 and 30 months of ICS treatment. ${ }^{55}$

This does not negate the benefit of triple therapy for patients with eosinophil counts lower than 150 cells $/ \mu \mathrm{L}$, since in IMPACT study the prespecified analysis of the effect of triple inhaled therapy on exacerbations showed a benefit in patients with counts below that threshold, although the exacerbations reduction was lower than that observed in patients with eosinophil counts higher than 150 cells $/ \mu \mathrm{L} .{ }^{6}$ However, a meta-analysis has recently reported an increased risk of pneumonia in patients with COPD and low eosinophil counts. ${ }^{56}$ Overall, it seems that low blood eosinophil levels may be a useful indicator of a lesser response to ICS. ${ }^{51,57}$ This is now considered in the 2019 update of the GOLD strategy document, in which a threshold of 100 cells $/ \mu \mathrm{L}$ is suggested to guide the decision not to step-up to triple therapy in patients who exacerbate when receiving LAMA/ LABA therapy. ${ }^{1}$ Further, the same document suggests that stepping-up to triple therapy could be of benefit to patients who exacerbate on LAMA/LABA therapy and who have blood eosinophil counts $\geq 100$ cells $/ \mu \mathrm{L}$, with a greater magnitude of response more likely in those with higher eosinophil counts (eg, $\geq 300$ cells $/ \mu \mathrm{L}$ ). ${ }^{1}$ 


\section{ICS/LABA vs LAMA/LABA}

The previous historical developments led to the first headto-head comparison of an ICS/LABA with a LAMA/LABA. Using exacerbations as the primary outcome, FLAME demonstrated a larger benefit from the dual bronchodilator indacaterol/glycopyrronium (IND/GLY) compared with the ICS/LABA combination of FLP/SAL, with the added benefit of higher $\mathrm{FEV}_{1}$ at lower risk of pneumonia. ${ }^{2}$ It is important to recognize that FLAME did not evaluate "step-up" in therapy, but a switch from one therapy to another. Furthermore, FLAME recruited patients with a history of exacerbations, suggesting that patients who were well controlled on ICS preparations were excluded, thereby biasing the selection to patients with poor response to ICS, who were thus likely to fail ICS maintenance therapy. These results, as well as the perceived risk of ICS-related side effects, led to the 2017 GOLD strategy document recommending ICS use should be reserved for selected patients with highly symptomatic COPD and a history of two or more exacerbations, or of one or more exacerbations resulting in hospitalization. ${ }^{58}$

\section{Review of triple therapy studies}

\section{Triple therapy in multiple inhalers}

Most studies evaluating the efficacy of "open triple" therapy, either adding a LAMA to a fixed ICS/LABA or vice versa, not only showed improvement in lung function compared with ICS/LABA or single LAMA therapy, but also improvements in health status, rescue medication use, and the risk of exacerbations, while maintaining a good safety profile. ${ }^{59-68}$ In contrast, in the 1-year WISDOM trial, which was designed to test ICS withdrawal from triple therapy (with all patients receiving triple therapy for 6 weeks prior to entry, then randomized to either continue triple therapy or withdraw ICS in three steps over 12 weeks), dual bronchodilation was as effective as triple therapy in terms of exacerbation prevention. ${ }^{69}$ In the patients randomized to withdraw ICS, there was a decrease of $38 \mathrm{~mL}$ of $\mathrm{FEV}_{1}$ at the end of WISDOM, although this stabilized over the subsequent year. ${ }^{69}$ However, all these open triple studies were short in duration, underpowered or retrospective, and required the use of at least two devices, sometimes of different handling characteristics. Nonetheless, triple therapy has become increasingly popular in clinical practice worldwide, ${ }^{70-73}$ suggesting a continuing need to improve symptom control and reduce the risk of exacerbations and hospitalization, particularly in patients with symptomatic COPD.

\section{Triple therapy in one inhaler}

Two different ICS/LABA/LAMA combinations in a single inhaler have been studied: the first comprises beclometasone dipropionate/formoterol fumarate/glycopyrronium bromide (BDP/FF/G; TRIMBOW ${ }^{\circledR}$, Chiesi Farmaceutici SpA) and the second includes fluticasone furoate/vilanterol/umeclidinium (FLF/VI/UMEC; TRELEGY ELLIPTA ${ }^{\circledR}$, GlaxoSmithKline).

$\mathrm{BDP} / \mathrm{FF} / \mathrm{G}$ has been developed as an extrafine formulation (aerosol particles with mass median aerodynamic diameter $<2 \mu \mathrm{m}$ ) in a pressurized metered-dose inhaler to deliver $87 / 5 / 9 \mu \mathrm{g}$ of BDP/FF/G, two inhalations twice daily. It is indicated in the European Union (EU) for maintenance treatment in adult patients with moderate-to-severe COPD who are not adequately treated by a combination of an ICS and a LABA.

FLF/VI/UMEC has been developed as a multidose drypowder inhaler (MDDPI) formulation to be delivered through the ELLIPTA device. Each single inhalation provides a delivered dose of 92/22/55 $\mu \mathrm{g}$ of FLF/VI/UMEC, at a recommended dose of one inhalation per day. In the EU, it is also indicated as a maintenance treatment in adult patients with moderate-to-severe COPD who are not adequately treated by a combination of an ICS and a LABA or a LABA and a LAMA. In the USA, FLF/VI/UMEC is indicated for the longterm, maintenance treatment of airflow obstruction in patients with COPD, and is also indicated to reduce exacerbations of COPD in patients with a history of exacerbations.

\section{The BDP/FF/G program}

The extrafine $\mathrm{BDP} / \mathrm{FF} / \mathrm{G}$ Phase III program included three 12-month studies (TRILOGY, TRINITY, and TRIBUTE), with a total of 2,529 patients with severe-to-very severe airflow limitation $\left(\mathrm{FEV}_{1}<50 \%\right.$ predicted) randomized to BDP/FF/G (Table 1). ${ }^{3-5}$ All patients included had a high symptom burden (COPD Assessment Test [CAT] $\geq 10$ ) and an exacerbation history ( $\geq 1$ exacerbation in the previous year). ${ }^{3-5}$ All three studies excluded patients who had received triple therapy in the previous year. Overall, the studies demonstrated improvements in $\mathrm{FEV}_{1}$, health status (St George's Respiratory Questionnaire, SGRQ) and reduction in the rate of moderate/severe exacerbations compared with ICS/LABA, LAMA monotherapy, and LAMA/LABA.

In the TRINITY study, the single inhaler BDP/FF/G combination was more effective than tiotropium alone, and was equally effective to the open triple combination of BDP/FF + tiotropium in terms of both predose $\mathrm{FEV}_{1}$ and the annual rate of moderate/severe exacerbations. ${ }^{5}$ In the TRILOGY study, compared to $\mathrm{BDP} / \mathrm{FF}, \mathrm{BDP} / \mathrm{FF} / \mathrm{G}$ showed a prolongation of the time to first clinical important deterioration (CID) as defined by any one of the following changes: decrease $\geq 100 \mathrm{~mL}$ from baseline in $\mathrm{FEV}_{1}$, deterioration $\geq 4$ units from baseline in SGRQ total score, deterioration $\geq 1$ unit from baseline in Transition Dyspnea Index focal score, occurrence of a moderate/severe 
Table I Overview of TRILOGY, ${ }^{4}$ TRINITY, ${ }^{5}$ and TRIBUTE ${ }^{3}$ studies (including pooled mortality data ${ }^{9}$ )

\begin{tabular}{|c|c|c|c|c|c|c|c|}
\hline \multirow[t]{2}{*}{ Treatment groups $^{a}$} & \multicolumn{2}{|l|}{ TRILOGY } & \multicolumn{3}{|l|}{ TRINITY } & \multicolumn{2}{|l|}{ TRIBUTE } \\
\hline & $\begin{array}{l}\text { BDP/FF/G } \\
(\mathbf{N}=687)\end{array}$ & $\begin{array}{l}\text { BDP/FF } \\
(N=680)\end{array}$ & $\begin{array}{l}\text { BDP/FF/G } \\
(\mathbf{N}=1,077)\end{array}$ & $\begin{array}{l}\text { Tiotropium } \\
(\mathbf{N}=1,074)\end{array}$ & $\begin{array}{l}\text { BDP/FF + } \\
\text { tiotropium } \\
(\mathbf{N}=\mathbf{5 3 8})\end{array}$ & $\begin{array}{l}\text { BDP/FF/G } \\
(\mathbf{N}=764)\end{array}$ & $\begin{array}{l}\text { IND/GLY } \\
(\mathbf{N}=768)\end{array}$ \\
\hline Run-in period & \multicolumn{2}{|c|}{2 weeks; BDP/FF } & \multicolumn{3}{|c|}{2 weeks; tiotropium } & \multicolumn{2}{|c|}{2 weeks; IND/GLY } \\
\hline Study duration & \multicolumn{2}{|c|}{12 months } & \multicolumn{3}{|c|}{12 months } & \multicolumn{2}{|c|}{12 months } \\
\hline Baseline characteristics & \multicolumn{7}{|c|}{$\begin{array}{l}\text { All patients had: } \\
\text { - } F E V_{1}<50 \% \\
\text { - } \geq I \text { moderate or severe exacerbation in the previous } 12 \text { mon } \\
\text { - } C A T \text { total score } \geq 10 \\
\text { - and were using ICS/LABA, ICS/LAMA, LAMA/LABA, or LAM } \\
\text { before screening } \\
\text { TRILOGY also required Baseline Dyspnea Index focal score } \geq 10\end{array}$} \\
\hline $\mathrm{FEV}_{1} \%$ predicted, mean (SD) & $36.9(8.4)$ & $36.2(8.6)$ & $36.6(8.3)$ & $36.6(8.1)$ & $36.7(8.3)$ & $36.4(8.0)$ & $36.4(8.1)$ \\
\hline $30 \%$ to $<50 \%$ & $77 \%$ & $77 \%$ & $79 \%$ & $79 \%$ & $79 \%$ & $80 \%$ & $79 \%$ \\
\hline$<30 \%$ & $23 \%$ & $23 \%$ & $21 \%$ & $21 \%$ & $21 \%$ & $20 \%$ & $21 \%$ \\
\hline Exacerbation history, rate (range) & $1.2(I-5)$ & $1.2(I-6)$ & $\mathrm{I} .3(\mathrm{I}-\mathrm{II})$ & I.3 (I-5) & $1.2(I-7)$ & $1.2(1-6)$ & $1.2(1-4)$ \\
\hline CAT, mean (SD) & $20.8(5.9)$ & $20.8(5.7)$ & $21.5(5.8)$ & $21.6(5.8)$ & $21.7(6.0)$ & $\begin{array}{r}\text { Not statec } \\
\text { criteria: } \geq 10\end{array}$ & $\begin{array}{l}\text { (inclusion } \\
\text { at screening) }\end{array}$ \\
\hline \multicolumn{8}{|l|}{ Results } \\
\hline \multicolumn{8}{|c|}{ Exacerbation rate (adjusted annualized) } \\
\hline Moderate/severe & 0.41 & 0.53 & 0.46 & 0.57 & 0.45 & 0.50 & 0.59 \\
\hline Rate ratio $(95 \% \mathrm{Cl})$ & \multicolumn{2}{|c|}{$0.77(0.65-0.92) ; P=0.005$} & \multicolumn{3}{|c|}{$\begin{array}{l}\text { BDP/FF/G vs tiotropium: } 0.80(0.69-0.92) \\
\qquad \begin{array}{l}P=0.0025^{b} \\
\text { BDP/FF/G vs BDP/FF + tiotropium: } \\
\text { I.0I }(0.85-1.21) ; P=0.89\end{array}\end{array}$} & \multicolumn{2}{|c|}{$\begin{array}{c}0.848(0.723-0.995) \\
P=0.043^{b}\end{array}$} \\
\hline Severe (hospitalizations) & 0.12 (unadjusted) & 0.14 (unadjusted) & 0.07 & 0.10 & 0.06 & 0.07 & 0.09 \\
\hline Rate ratio $(95 \% \mathrm{Cl})$ & \multicolumn{2}{|c|}{ Not stated } & \multicolumn{3}{|c|}{ 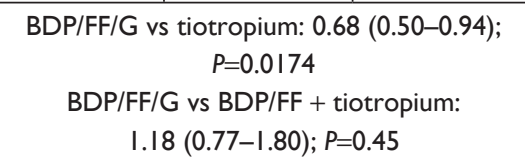 } & \multicolumn{2}{|c|}{$\begin{array}{c}0.787(0.55 \mathrm{I}-\mathrm{I} .125) \\
P=0.189\end{array}$} \\
\hline \multicolumn{8}{|c|}{ Predose $\mathrm{FEV}_{1}$ change from baseline, $\mathrm{L}$} \\
\hline Week 26 & 0.082 & 0.001 & Not stated & Not stated & Not stated & Not stated & Not stated \\
\hline Mean difference $(95 \% \mathrm{Cl})$ & \multicolumn{2}{|c|}{$0.08 \mathrm{I}(0.052-0.109) ; P<0.00 I^{\mathrm{c}}$} & \multicolumn{3}{|c|}{$\begin{array}{l}\text { BDP/FF/G vs tiotropium: } P<0.00 \text { I } \\
\text { BDP/FF/G vs BDP/FF + tiotropium: } P=N S\end{array}$} & \multicolumn{2}{|c|}{$0.020 ; P=\mathrm{NS}$} \\
\hline Week 52 & 0.071 & 0.008 & 0.082 & 0.021 & 0.085 & Not stated & Not stated \\
\hline Mean difference $(95 \% \mathrm{Cl})$ & \multicolumn{2}{|c|}{$0.063(0.032-0.094) ; P<0.001$} & \multicolumn{3}{|c|}{$\begin{array}{l}\text { BDP/FF/G vs tiotropium: } \\
0.06 \text { I }(0.037-0.086) ; P<0.000 \text { I } \\
\text { BDP/FF/G vs BDP/FF + tiotropium: }-0.003 \\
(-0.033 \text { to } 0.027) ; P=0.85\end{array}$} & \multicolumn{2}{|c|}{$0.019 ; P=\mathrm{NS}$} \\
\hline $\begin{array}{l}\text { SGRQ total score change } \\
\text { from baseline at Week } 52\end{array}$ & Not stated & Not stated & Not stated & Not stated & Not stated & Not stated & Not stated \\
\hline Mean difference $(95 \% \mathrm{Cl})$ & \multicolumn{2}{|c|}{$-1.69(-3.20$ to -0.17$) ; P=0.029$} & \multicolumn{3}{|c|}{$\begin{array}{c}\text { BDP/FF/G vs tiotropium: } P<0.05 \\
\text { BDP/FF/G vs BDP/FF + tiotropium: } P<0.05 \\
(\mathrm{BDP} / \mathrm{FF}+\text { tiotropium superior to } \mathrm{BDP} / \mathrm{FF} / \mathrm{G})\end{array}$} & \multicolumn{2}{|c|}{$-1.64 ; P<0.01$} \\
\hline $\begin{array}{l}\text { Patients with pneumonia } \\
\text { adverse event, } \mathrm{n}(\%)\end{array}$ & $23(3)$ & $18(3)$ & $28(3)$ & $19(2)$ & $12(2)$ & $28(4)$ & $27(4)$ \\
\hline All-cause mortality & $2.2 \%$ & $2.4 \%$ & $1.9 \%$ & $2.7 \%$ & $1.5 \%$ & $2.1 \%$ & $2.7 \%$ \\
\hline Hazard ratio $(95 \% \mathrm{Cl})$ & \multicolumn{7}{|c|}{$\begin{array}{l}\text { Pooled data } \\
\text { BDP/FF/G, BDP/FF and BDP/FF + tiotropium }(\mathrm{N}=3,745) \text { vs tiotropium and IND/GLY }(\mathrm{N}=\mathrm{I}, 844) \text { : } \\
0.7 \mathrm{I}(0.50-\mathrm{I} .02) ; P=0.066 \\
\mathrm{BDP} / \mathrm{FF} / \mathrm{G}(\mathrm{N}=2,528) \text { vs tiotropium and IND/GLY }(\mathrm{N}=\mathrm{I}, 844): 0.72(0.49-1.06) ; P=0.096\end{array}$} \\
\hline
\end{tabular}

Notes: ${ }^{2} \mathrm{~N}$ values are the number of patients in the intention-to-treat population; ${ }^{b}$ primary endpoint of the study; ' $\mathrm{c}$ (ne of three coprimary endpoints (the others were change from baseline in 2-hour postdose FEV and Transition Dyspnea Index total score, both at Week 26).

Abbreviations: BDP/FF/G, beclometasone dipropionate/formoterol fumarate/glycopyrronium; CAT, COPD Assessment Test; ICS, inhaled corticosteroid; IND/GLY, indacaterol/glycopyrronium; LABA, long-acting $\beta_{2}$-agonist; LAMA, long-acting muscarinic antagonist; NS, not significant; SGRQ, St George's Respiratory Questionnaire. 
COPD exacerbation, or death. ${ }^{74}$ Furthermore, in the subgroup of patients in TRILOGY classified as GOLD 2017 Group B (ie, those with CAT score $\geq 10$ and one exacerbation in the previous year not leading to hospitalization or emergency room admission), BDP/FF/G reduced the rate of moderate/severe exacerbations compared to BDP/FF. ${ }^{75}$ These results were consistent with those observed in TRINITY, where BDP/FF/G delayed CID compared to tiotropium, and reduced the rate of moderate/severe exacerbations in GOLD Group B patients. ${ }^{75,76}$ In TRIBUTE, in addition to confirming the delay of $\mathrm{CID},{ }^{77}$ and the benefits in GOLD Group B patients, ${ }^{78} \mathrm{BDP} / \mathrm{FF} / \mathrm{G}$ demonstrated a favorable benefit/risk ratio compared with the dual bronchodilator combination IND/GLY; ${ }^{3}$ in particular, there was a reduced rate of moderate/severe exacerbations together with comparable rates of pneumonia events, as shown in Figure $1 .^{79}$

Interestingly, a pooled post hoc analysis of the three studies showed that BDP/FF/G reduced the number of fatal events by $32 \%$ compared to the non-ICS-containing reference arms (IND/GLY or tiotropium), although statistical significance was missed $(P=0.096)$ due to the overall relatively small number of events. ${ }^{9}$

\section{The FLF/VI/UMEC program}

The pivotal phase of the clinical development of FLF/VI/ UMEC consisted of two main studies, FULFIL and IMPACT. Essentially, they provided consistent evidence of improvements in $\mathrm{FEV}_{1}$ and health status, and a reduction in annual exacerbation rate compared to the reference comparators (Table 2). ${ }^{6,7}$ In these studies, a total of 5,062 patients were randomized to FLF/VI/UMEC, all of whom had symptomatic
COPD $(C A T \geq 10)$, but with the other main inclusion criteria differing slightly (Table 2). The FULFIL study compared FLF/VI/UMEC with BUD/FF MDDPI fixed combination for 24 weeks in patients with severe airflow limitation but no increased risk of exacerbations and patients with moderate airflow limitation but highly increased risk of exacerbations. ${ }^{7}$ The study showed superiority of the triple combination on $\mathrm{FEV}_{1}$ and health status. A subgroup of about $24 \%$ of patients entered into an extension phase up to 52 weeks, in whom there was a reduction in the exacerbation rate with FLF/VI/UMEC compared with BUD/FF. ${ }^{7}$ In the IMPACT study, FLF/VI/ UMEC was compared with FLF/VI and UMEC/VI, all delivered via the ELLIPTA device. ${ }^{6}$ The study showed a reduced exacerbation rate with triple therapy compared with the two dual therapies, as well as a benefit on $\mathrm{FEV}_{1}$ and health status. The large sample size of IMPACT (more than 10,000 patients randomized overall) meant that the study could demonstrate that all-cause mortality was lower with the regimens containing the ICS FLF (triple therapy and FLF/VI) than with the LAMA/LABA UMEC/VI. ${ }^{6,8}$ This result is consistent with the trend observed with the pooled post hoc analysis of the BDP/ FF/G studies, suggesting that triple ICS-containing regimens do have an impact on mortality in patients with symptomatic COPD and an exacerbation history.

The inclusion of patients with potential concomitant asthma in the triple therapy programs

One of the criticisms of the TRIBUTE and IMPACT studies was the recruitment of patients with a history of asthma (although not current asthma) - and the consequent potential

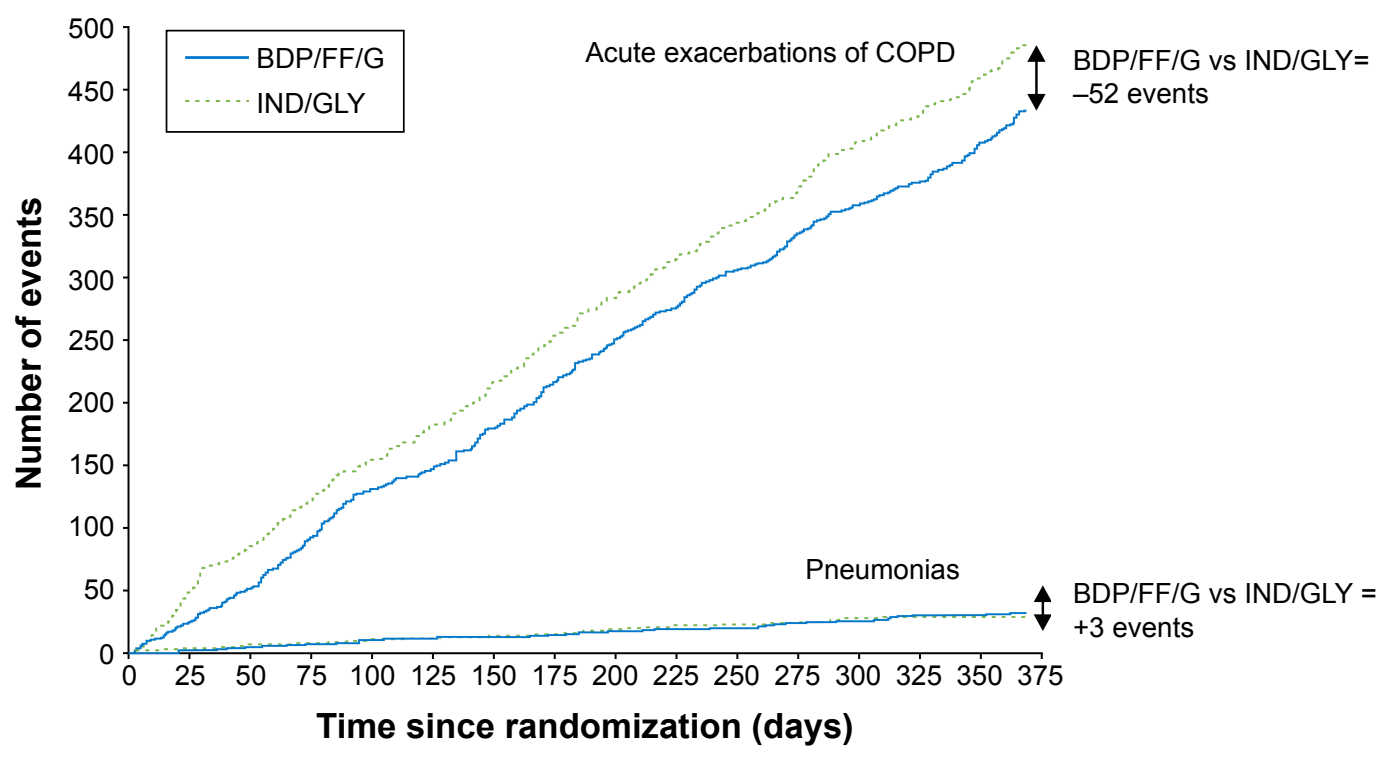

Figure I The overall benefit/risk ratio (ie, exacerbations/pneumonia) in the TRIBUTE study.

Note: Reproduced with permission from Scuri M, Singh D, Fabbri LM, et al. Risk of pneumonia and exacerbations with single inhaler extrafine triple therapy compared to indacaterol/glycopyrronium: post-hoc analysis of the TRIBUTE study. Am J Respir Crit Care Med. 2018; 197:A3030. ${ }^{79}$

Abbreviations: BDP/FF/G, beclometasone dipropionate/formoterol fumarate/glycopyrronium; IND/GLY, indacaterol/glycopyrronium. 
Table 2 Overview of FULFIL ${ }^{7}$ and IMPACT ${ }^{6}$ studies (including IMPACT mortality data ${ }^{8}$ )

\begin{tabular}{|c|c|c|c|c|c|}
\hline \multirow[t]{2}{*}{ Treatment groups $^{a}$} & \multicolumn{2}{|l|}{ FULFIL } & \multicolumn{3}{|l|}{ IMPACT } \\
\hline & $\begin{array}{l}\text { FLF/VI/UMEC } \\
(\mathbf{N}=9 \mid I)\end{array}$ & $\begin{array}{l}\text { BUD/FF } \\
(\mathbf{N}=899)\end{array}$ & $\begin{array}{l}\text { FLF/VI/UMEC } \\
(\mathrm{N}=4,151)\end{array}$ & $\begin{array}{l}\text { FLF/VI } \\
(\mathrm{N}=4,134)\end{array}$ & $\begin{array}{l}\text { UMEC/VI } \\
(\mathrm{N}=\mathbf{2 , 0 7 0})\end{array}$ \\
\hline Run-in period & \multicolumn{2}{|c|}{2 weeks; medication unchanged from screening } & \multicolumn{3}{|c|}{2 weeks; medication unchanged from screening } \\
\hline Study duration & \multicolumn{2}{|c|}{$\begin{array}{l}24 \text { weeks, with extension to } 52 \text { weeks ( } \mathrm{N}=210 \text { and } \\
220 \text { for FLF/UMEC/VI and BUD/FF, respectively) }\end{array}$} & \multicolumn{3}{|c|}{52 weeks } \\
\hline Baseline characteristics & \multicolumn{2}{|c|}{$\begin{array}{l}\text { All patients had CAT } \geq 10 \text { and: } \\
\text { I. FEV },<50 \% \text {, or } \\
\text { 2. } F E V_{1} \geq 50 \% \text { to }<80 \% \text {, and } \geq 2 \text { moderate } \\
\quad \text { exacerbations or } \geq 1 \text { severe exacerbation } \\
\text { in the past year } \\
\text { (Patients were required to be taking daily COPD } \\
\text { maintenance therapy for at least } 3 \text { months } \\
\text { prior to screening) }\end{array}$} & \multicolumn{3}{|c|}{$\begin{array}{l}\text { All patients had CAT } \geq 10 \text { and: } \\
\text { I. } F E V_{1}<50 \% \text { and } \geq I \text { moderate or severe } \\
\text { exacerbation in the past year, or } \\
\text { 2. } F E V_{1} \geq 50 \% \text { to }<80 \% \text { and } \geq 2 \text { moderate } \\
\text { exacerbations or } \geq I \text { severe exacerbation } \\
\text { in the past year } \\
\text { (LABA, LAMA or ICS permitted as prior medication, } \\
\text { alone or in any combination) }\end{array}$} \\
\hline FEV, \% predicted, mean (SD) & $45.5(12.97)$ & $45.1(13.64)$ & $45.7(15.0)$ & $45.5(14.8)$ & $45.4(14.7)$ \\
\hline$\geq 80 \%$ & Not stated & Not stated & $<1 \%$ & $<1 \%$ & $<1 \%$ \\
\hline $50 \%$ to $<80 \%$ & Not stated & Not stated & $37 \%$ & $35 \%$ & $35 \%$ \\
\hline $30 \%$ to $<50 \%$ & Not stated & Not stated & $47 \%$ & $49 \%$ & $49 \%$ \\
\hline$<30 \%$ & Not stated & Not stated & $16 \%$ & $15 \%$ & $15 \%$ \\
\hline $\begin{array}{l}\text { Exacerbation history, rate } \\
\text { (range) }\end{array}$ & Not stated & Not stated & Not stated & Not stated & Not stated \\
\hline CAT, mean (SD) & Not stated & Not stated & $20.1(6.1)$ & $20.1(6.1)$ & $20.2(6.2)$ \\
\hline \multicolumn{6}{|l|}{ Results } \\
\hline \multicolumn{6}{|c|}{ Exacerbation rate (adjusted annualized) } \\
\hline Moderate/severe & 0.22 & 0.34 & 0.91 & 1.07 & 1.21 \\
\hline Rate ratio $(95 \% \mathrm{Cl})$ & \multicolumn{2}{|c|}{$0.65(0.49-0.86) ; P=0.002^{b}$} & \multicolumn{3}{|c|}{$\begin{array}{l}\text { FLF/UMEC/VI vs FLF/VI: } 0.85(0.80-0.90) ; P<0.00 I^{\prime} \\
\text { FLF/UMEC/VI vs UMEC/VI: } 0.75(0.70-0.8 \mathrm{I}) ; P<0.00 \mathrm{I}^{\mathrm{c}}\end{array}$} \\
\hline Severe (hospitalizations) & I\% (over 24 weeks) & $2 \%$ (over 24 weeks) & 0.13 & 0.15 & 0.19 \\
\hline Rate ratio $(95 \% \mathrm{Cl})$ & \multicolumn{2}{|c|}{ Not stated } & \multicolumn{3}{|c|}{$\begin{array}{l}\text { FLF/UMEC/VI vs FLF/VI: } 0.87(0.76-1.01) ; P=0.06 \\
\text { FLF/UMEC/VI vs UMEC/VI: } 0.66(0.56-0.78) ; P<0.00 \text { I }\end{array}$} \\
\hline \multicolumn{6}{|c|}{ Predose FEV, change from baseline (L) } \\
\hline Week 24 & 0.142 & -0.029 & Not stated & Not stated & Not stated \\
\hline Mean difference $(95 \% \mathrm{Cl})$ & \multicolumn{2}{|c|}{$0.17 \mid(0.148-0.194) ; P<0.00 I^{d}$} & \multicolumn{3}{|c|}{ Not stated } \\
\hline Week 52 & 0.126 & -0.053 & 0.094 & -0.003 & 0.040 \\
\hline Mean difference $(95 \% \mathrm{Cl})$ & \multicolumn{2}{|c|}{$0.179(0.131-0.226) ; P<0.001$} & \multicolumn{3}{|c|}{$\begin{array}{l}\text { FLF/UMEC/VI vs FLF/VI: } 0.097(0.085-0.109) ; P<0.00 \text { I } \\
\text { FLF/UMEC/VI vs UMEC/VI: } 0.054(0.039-0.069) ; P<0.00 \text { I }\end{array}$} \\
\hline \multicolumn{6}{|c|}{ SGRQ total score change from baseline } \\
\hline Week 24 & -6.6 & -4.3 & Not stated & Not stated & Not stated \\
\hline Mean difference $(95 \% \mathrm{Cl})$ & \multicolumn{2}{|c|}{$-2.2(-3.5$ to -1.0$) ; P<0.00 I^{d}$} & \multicolumn{3}{|c|}{ Not stated } \\
\hline Week 52 & -4.6 & -1.9 & -5.5 & -3.7 & -3.7 \\
\hline Mean difference $(95 \% \mathrm{Cl})$ & \multicolumn{2}{|c|}{$-2.7(-5.5$ to 0.2$) ; P=0.065$} & \multicolumn{3}{|c|}{$\begin{array}{l}\text { FLF/UMEC/VI vs FLF/VI: }-1.8(-2.4 \text { to }-1.1) ; P<0.00 \text { I } \\
\text { FLF/UMEC/VI vs UMEC/VI: }-1.8(-2.6 \text { to }-1.0) ; P<0.00 \text { I }\end{array}$} \\
\hline $\begin{array}{l}\text { Patients with pneumonia adverse } \\
\text { event of special interest, } n(\%)\end{array}$ & 20 (2.2) (over 24 weeks) & 7 (0.8) (over 24 weeks) & $317(8)$ & $292(7)$ & $97(5)$ \\
\hline Hazard ratio $(95 \% \mathrm{Cl})$ & \multicolumn{2}{|c|}{ Not stated } & \multicolumn{3}{|c|}{$\begin{array}{l}\text { FLF/UMEC/VI vs FLF/VI: I.02 (0.87-I.19); } P=0.85 \\
\text { FLF/UMEC/VI vs UMEC/VI: I.53 (I.22-I.92); } P<0.00 \text { I }\end{array}$} \\
\hline All-cause mortality & \multicolumn{2}{|c|}{$\begin{array}{l}\text { Six on-treatment deaths in each arm; annualized data } \\
\text { not reported }\end{array}$} & $1.20 \%$ & $1.19 \%$ & $1.88 \%$ \\
\hline Hazard ratio $(95 \% \mathrm{Cl})$ & \multicolumn{2}{|c|}{ Not stated } & \multicolumn{3}{|c|}{$\begin{array}{l}\text { FLF/UMEC/VI vs FLF/VI: } 0.945 \text { (0.637-I.402); } P=0.780 \\
\text { FLF/UMEC/VI vs UMEC/VI: } 0.579 \text { (0.38I-0.88I); } P=0.01 \text { I }\end{array}$} \\
\hline
\end{tabular}

Notes: a $\mathrm{N}$ values are the number of patients in the intention-to-treat population; b ${ }^{\text {data }}$ are for the intention-to-treat population; in the extension population, the moderate/ severe exacerbation rates were 0.20 and 0.36 for FLF/UMEC/VI and BUD/FF, respectively, with a rate ratio of 0.56 ( $95 \% \mathrm{Cl} 0.37-0.85)$; $P=0.006$; ' the two comparisons were coprimary endpoints of the study; ${ }^{\mathrm{d}}$ coprimary endpoints.

Abbreviations: BUD/FF, budesonide/formoterol fumarate; CAT, COPD Assessment Test; FLF/UMEC/VI, fluticasone furoate/umeclidinium/vilanterol; ICS, inhaled corticosteroid; LABA, long-acting $\beta_{2}$-agonist; LAMA, long-acting muscarinic antagonist; SGRQ, St George's Respiratory Questionnaire. 
influence on the overall results of the studies. Indeed, in the editorial commentary that was published with the IMPACT study, Suissa and Drazen suggest that the inclusion of patients with a history of asthma, and more specifically the potential abrupt withdrawal of ICS in case of randomization to the LAMA/LABA arm, might have triggered exacerbations, hence exaggerating the benefit in favor of triple therapy. ${ }^{80}$ However, it should be emphasized that patients included in these studies had poor lung function even after bronchodilation (especially in TRIBUTE study), so regardless of their asthma history, their COPD should be considered as the prevalent medical condition.

\section{Pneumonia in the triple therapy programs}

Since, by definition, all triple therapy regimens include ICS, the potential increased risk of infective events should be weighed against the advantages over bronchodilator therapies. The risk of pneumonia in TRILOGY was similar (3\%) in the two arms, both of which contained ICS, ie, BDP/FF/G and $\mathrm{BDP} / \mathrm{FF} .{ }^{4}$ In the TRINITY study, the incidence of pneumonia was similar in the three treatment groups $(3 \%, 2 \%$, and $2 \%$ for $\mathrm{BDP} / \mathrm{FF} / \mathrm{G}$, tiotropium, and $\mathrm{BDP} / \mathrm{FF}$ + tiotropium, respectively). ${ }^{5}$ Similar results were seen in the TRIBUTE study, where the pneumonia incidence was not different in patients treated with either BDP/FF/G or IND/GLY (4\% for both). ${ }^{3}$ This result contrasts with FLAME, in which 1 year treatment with FLP/SAL was associated with a greater incidence of pneumonia (4.8\%) than IND/GLY $(3.2 \% ; P=0.02) .{ }^{2}$ Further, in the 6-month FULFIL trial the risk of pneumonia was higher in patients treated with FLF/UMEC/VI than BUD/FF ( $2.2 \%$ vs $0.8 \%$, respectively). ${ }^{7}$ Similarly, in IMPACT study patients treated with FLF/VI/UMEC had a higher incidence of pneumonia ( $8 \%$ ) compared to UMEC/VI $(5 \% ; P<0.001)$ and similar incidence to that of patients treated with FLF/ VI $(7 \% ; P=0.85) .{ }^{6}$ This might suggest that the dose, pharmacological characteristics, such as the size or extent of the immunosuppressive effect, ${ }^{81}$ or particle size of different ICS molecules, may influence the risk of ICS-associated pneumonia events; indeed, in a cohort database study, patients with obstructive lung disease who received extrafine ICS had a lower risk of pneumonia than those who received fine-particle ICS. ${ }^{82}$ Interestingly, the 1-year WISDOM study showed no increased risk of pneumonia in the ICS maintenance group (tiotropium plus FLP/SAL) compared to the ICS withdrawal group (tiotropium plus SAL; 5.8\% and 5.5\%, respectively), ${ }^{69}$ nor did the 6-month SUNSET study $(1.7 \%$ and $1.1 \%$ in the maintenance [tiotropium plus FLP/SAL] vs ICS withdrawal groups [IND/GLY], respectively).$^{52}$ None of the cited studies showed an increased risk of respiratory tract infections other than pneumonia.

\section{Triple therapy and survival}

The most frustrating aspect of the management of COPD is the lack of solid evidence of effect of any pharmacologic treatment on mortality. As discussed above, the only two large properly designed RCTs showed a decrease in risk of death that was borderline significant, ${ }^{23}$ or not statistically significant. ${ }^{25}$ Both studies compared a combination of ICS/LABA with placebo and with each of the components. However, an analysis of the large UPLIFT trial suggested a potential beneficial effect on mortality of tiotropium added to usual care. ${ }^{24}$

The data emerging from the triple combination studies cited above provide a glimmer of hope. Even though the studies were not designed to evaluate the effect of triple therapy on survival, in IMPACT study there was a significant survival difference in favor of the triple combination compared with the dual bronchodilator therapy and a smaller, but still important difference compared with the ICS/LABA combination. ${ }^{6,9}$ Most patients included in these studies had moderate, severe, and very severe airflow limitation and a history of exacerbations, many having been hospitalized for respiratory failure, with significant compromise. It is hoped that future trials designed to evaluate the effect of triple vs dual combinations with mortality as an outcome will provide an answer to this important question. Finally, it is important to note that proper management of frequently presenting concomitant chronic diseases like chronic heart failure, ischemic heart disease, stroke, diabetes, and hypertension is needed to improve overall patient outcomes. ${ }^{83}$

\section{Who should be treated with triple therapy?}

As mentioned previously, BDP/FF/G and FLF/VI/UMEC are both approved in the EU as maintenance treatments in adult patients with moderate-to-severe COPD who are not adequately treated by a combination of an ICS and a LABA (with FLF/VI/UMEC also approved for patients inadequately treated with a LABA and a LAMA), whereas in the USA, FLF/VI/UMEC is approved for the long-term, maintenance treatment of airflow obstruction in patients with COPD, and is also indicated to reduce exacerbations of COPD in patients with a history of exacerbations. These slightly different indications have in common that triple therapy is recommended for patients not adequately controlled by existing inhaled therapies. Neither the European Medicines Agency nor the US Food and Drug Administration make a distinction between initiation 
of therapy in untreated newly diagnosed patients compared with use of triple therapy in already treated patients, as both organizations assume triple therapy is used as a step-up. Similarly, the GOLD strategy document recommends triple therapy only as a step-up from LAMA/LABA or ICS/LABA in GOLD Group D patients whose disease is not adequately controlled by LAMA/LABA or ICS/LABA. ${ }^{1}$ However, due to changes over time in the GOLD definition of high exacerbation risk, the studies performed with triple therapy in a single inhaler have recruited patients who, according to the 2017 definition, would be a mixture of GOLD Group B and D..$^{3-7}$ Thus in clinical practice, the use of triple therapy might be considered beneficial not only in GOLD Group D patients but also in patients at lower risk of exacerbations, eg, symptomatic patients with at least one moderate exacerbation. Triple therapy may even be of benefit in patients who have not exacerbated, although this will need confirming in other studies. ${ }^{84}$

\section{Concluding remarks}

The most recent studies of ICS combined with LABA and LAMA in a single inhaler showed that triple therapy represents the most potent pharmacological treatment available for patients with COPD with moderate-to-very severe airflow limitation, particularly those with an exacerbation history. Compared to LAMA, ICS/LABA, or LAMA/LABA, triple therapy not only has been shown to improve lung function, health status, rescue medication use, and risk of exacerbations, but also for the first time shows a promising signal on improved survival.

\section{Acknowledgments}

The authors thank David Young of Young Medical Communications and Consulting Ltd., for providing writing support. This review was funded by Chiesi Farmaceutici SpA.

\section{Disclosure}

LV reports grants and personal fees from AstraZeneca, grants from Philips, and Fisher and Paykel, and personal fees from Chiesi, GSK, Pulmonx, Menarini, and Boehringer-Ingelheim, all outside the submitted work. LMF reports grants, personal fees, and nonfinancial support from Boehringer-Ingelheim, Chiesi Farmaceutici, GlaxoSmithKline, Merck Sharp \& Dohme, Takeda, AstraZeneca, Novartis, Menarini, Laboratori Guidotti, and Almirall, personal fees and nonfinancial support from Pearl Therapeutics, Mundipharma, and Boston Scientific, personal fees from Kyorin, Bayer, and Zambon, and grants from Pfizer, Dompè, Malesci, Alfasigma, and Vree Health Italia, all outside the submitted work. AP reports grants, personal fees, nonfinancial support, advisory board membership and consultancy work from Chiesi, AstraZeneca,
GlaxoSmithKline, Boehringer-Ingelheim, Mundipharma, and TEVA, personal fees and nonfinancial support from Menarini, Novartis, and Zambon, and grants from Sanofi, all outside the submitted work. SP is employed by Chiesi, the sponsor of TRILOGY, TRINITY, and TRIBUTE. BC reports grants to the Division of Pulmonary and Critical Care from AstraZeneca, and that he is a consultant for GlaxoSmithKline, Boehringer-Ingelheim, AstraZeneca, Novartis, Pulmonix, Chiesi, and Menarini, all outside the submitted work. The authors report no other conflicts of interest in this work.

\section{References}

1. Global Initiative for Chronic Obstructive Lung Disease. Global strategy for the diagnosis, management, and prevention of chronic obstructive pulmonary disease. Available from: www.goldcopd.org. Published 2019. Accessed November 19, 2018.

2. Wedzicha JA, Banerji D, Chapman KR, et al. Indacaterol-glycopyrronium versus salmeterol-fluticasone for COPD. N Engl J Med. 2016;374(23): 2222-2234.

3. Papi A, Vestbo J, Fabbri L, et al. Extrafine inhaled triple therapy versus dual bronchodilator therapy in chronic obstructive pulmonary disease (TRIBUTE): a double-blind, parallel group, randomised controlled trial. Lancet. 2018;391(10125):1076-1084.

4. Singh D, Papi A, Corradi M, et al. Single inhaler triple therapy versus inhaled corticosteroid plus long-acting $\beta_{2}$-agonist therapy for chronic obstructive pulmonary disease (TRILOGY): a double-blind, parallel group, randomised controlled trial. Lancet. 2016;388(10048):963-973.

5. Vestbo J, Papi A, Corradi M, et al. Single inhaler extrafine triple therapy versus long-acting muscarinic antagonist therapy for chronic obstructive pulmonary disease (TRINITY): a double-blind, parallel group, randomised controlled trial. Lancet. 2017;389(10082):1919-1929.

6. Lipson DA, Barnhart F, Brealey N, et al. Once-daily single-inhaler triple versus dual therapy in patients with COPD. N Engl J Med. 2018; 378(18):1671-1680.

7. Lipson DA, Barnacle H, Birk R, et al. FULFIL Trial: once-daily triple therapy for patients with chronic obstructive pulmonary disease. $\mathrm{Am} J$ Respir Crit Care Med. 2017;196(4):438-446.

8. Lipson DA, Barnhart F, Brealey N. Reduction in all-cause mortality with single inhaler triple therapy (FF/UMEC/VI) versus dual therapy (FF/VI and UMEC/VI) in symptomatic patients with COPD: prespecified analysis of the Phase III IMPACT Trial. Am J Respir Crit Care Med. 2018;197:A1015.

9. Vestbo J, Fabbri L, Papi A, et al. Inhaled corticosteroid containing combinations and mortality in COPD. Eur Respir J. 2018;1801230.

10. Standards for the diagnosis and care of patients with chronic obstructive pulmonary disease. American Thoracic Society. Am J Respir Crit Care Med. 1995;152(5 Pt 2):S77-S121.

11. O'Donnell DE, Flüge T, Gerken F, et al. Effects of tiotropium on lung hyperinflation, dyspnoea and exercise tolerance in COPD. Eur Respir J. 2004;23(6):832-840.

12. Hohlfeld JM, Vogel-Claussen J, Biller H, et al. Effect of lung deflation with indacaterol plus glycopyrronium on ventricular filling in patients with hyperinflation and COPD (CLAIM): a double-blind, randomised, crossover, placebo-controlled, single-centre trial. Lancet Respir Med. 2018;6(5):368-378.

13. Casaburi R, Mahler DA, Jones PW, et al. A long-term evaluation of once-daily inhaled tiotropium in chronic obstructive pulmonary disease. Eur Respir J. 2002;19(2):217-224.

14. Niewoehner DE, Rice K, Cote C, et al. Prevention of exacerbations of chronic obstructive pulmonary disease with tiotropium, a once-daily inhaled anticholinergic bronchodilator: a randomized trial. Ann Intern Med. 2005;143(5):317-326.

15. Tashkin DP, Celli B, Senn S, et al. A 4-year trial of tiotropium in chronic obstructive pulmonary disease. N Engl J Med. 2008;359(15):1543-1554. 
16. Salpeter SR, Ormiston TM, Salpeter EE. Cardiovascular effects of betaagonists in patients with asthma and COPD: a meta-analysis. Chest. 2004;125(6):2309-2321.

17. Singh S, Loke YK, Furberg CD, Review AS. Inhaled anticholinergics and risk of major adverse cardiovascular events in patients with chronic obstructive pulmonary disease: a systematic review and meta-analysis. JAMA. 2008;300(12):1439-1450.

18. Gershon A, Croxford R, Calzavara A, et al. Cardiovascular safety of inhaled long-acting bronchodilators in individuals with chronic obstructive pulmonary disease. JAMA Intern Med. 2013;173(13):1175-1185.

19. Wilchesky M, Ernst P, Brophy JM, Platt RW, Suissa S. Bronchodilator use and the risk of arrhythmia in COPD: part 1: Saskatchewan cohort study. Chest. 2012;142(2):298-304.

20. Wilchesky M, Ernst P, Brophy JM, Platt RW, Suissa S. Bronchodilator use and the risk of arrhythmia in COPD: part 2: reassessment in the larger Quebec cohort. Chest. 2012;142(2):305-311.

21. Calverley PM, Anderson JA, Celli B, et al. Cardiovascular events in patients with COPD: TORCH study results. Thorax. 2010;65(8):719-725.

22. Suissa S, Dell'aniello S, Ernst P. Long-acting bronchodilator initiation in COPD and the risk of adverse cardiopulmonary events. Chest. 2017;151(1):60-67.

23. Calverley PM, Anderson JA, Celli B, et al. Salmeterol and fluticasone propionate and survival in chronic obstructive pulmonary disease. N Engl J Med. 2007;356(8):775-789.

24. Celli B, Decramer M, Kesten S, et al. Mortality in the 4-year trial of tiotropium (UPLIFT) in patients with chronic obstructive pulmonary disease. Am J Respir Crit Care Med. 2009;180(10):948-955.

25. Vestbo J, Anderson JA, Brook RD, et al. Fluticasone furoate and vilanterol and survival in chronic obstructive pulmonary disease with heightened cardiovascular risk (SUMMIT): a double-blind randomised controlled trial. Lancet. 2016;387(10030):1817-1826.

26. Oba Y, Sarva ST, Dias S. Efficacy and safety of long-acting $\beta$-agonist/ long-acting muscarinic antagonist combinations in COPD: a network meta-analysis. Thorax. 2016;71(1):15-25.

27. Suissa S, Dell'Aniello S, Ernst P. Concurrent use of long-acting bronchodilators in COPD and the risk of adverse cardiovascular events. Eur Respir J. 2017;49(5):1602245.

28. Calzetta L, Rogliani P, Matera MG, Cazzola M. A systematic review with meta-analysis of dual bronchodilation with LAMA/LABA for the treatment of stable COPD. Chest. 2016;149(5):1181-1196.

29. Calverley PMA, Anzueto AR, Carter K, et al. Tiotropium and olodaterol in the prevention of chronic obstructive pulmonary disease exacerbations (DYNAGITO): a double-blind, randomised, parallel-group, active-controlled trial. Lancet Respir Med. 2018;6(5):337-344.

30. [No authors listed]. Standards for the diagnosis and care of patients with chronic obstructive pulmonary disease (COPD) and asthma. This official statement of the American Thoracic Society was adopted by the ATS Board of Directors, November 1986. Am Rev Respir Dis. 1987;136(1):225-244.

31. Brown HM, Storey G, George WH. Beclomethasone dipropionate: a new steroid aerosol for the treatment of allergic asthma. $\mathrm{Br}$ Med J. 1972;1(5800):585-590.

32. Pauwels RA, Buist AS, Calverley PMA, Jenkins CR, Hurd SS. Global strategy for the diagnosis, management, and prevention of chronic obstructive pulmonary disease. Am J Respir Crit Care Med. 2001;163(5): 1256-1276.

33. Celli BR, MacNee W. ATS/ERS Task Force. Standards for the diagnosis and treatment of patients with COPD: a summary of the ATS/ERS position paper. Eur Respir J. 2004;23(6):932-946.

34. Burrows B, Bloom JW, Traver GA, Cline MG. The course and prognosis of different forms of chronic airways obstruction in a sample from the general population. N Engl J Med. 1987;317(21):1309-1314.

35. Kerstjens HA, Brand PL, Hughes MD, et al. A comparison of bronchodilator therapy with or without inhaled corticosteroid therapy for obstructive airways disease. Dutch Chronic Non-Specific Lung Disease Study Group. N Engl J Med. 1992;327(20):1413-1419.
36. Djukanović R, Wilson JW, Britten KM, et al. Effect of an inhaled corticosteroid on airway inflammation and symptoms in asthma. Am Rev Respir Dis. 1992;145(3):669-674.

37. Fabbri LM, Romagnoli M, Corbetta L, et al. Differences in airway inflammation in patients with fixed airflow obstruction due to asthma or chronic obstructive pulmonary disease. Am J Respir Crit Care Med. 2003;167(3):418-424.

38. Pauwels RA, Löfdahl CG, Laitinen LA, et al. Long-term treatment with inhaled budesonide in persons with mild chronic obstructive pulmonary disease who continue smoking. European Respiratory Society Study on Chronic Obstructive Pulmonary Disease. NEngl J Med. 1999;340(25): 1948-1953.

39. Vestbo J, Sørensen T, Lange P, Brix A, Torre P, Viskum K. Long-term effect of inhaled budesonide in mild and moderate chronic obstructive pulmonary disease: a randomised controlled trial. Lancet. 1999; 353(9167):1819-1823.

40. Lung Health Study Research Group, Wise R, Connett J, Weinmann G, Scanlon P, Skeans M. Effect of inhaled triamcinolone on the decline in pulmonary function in chronic obstructive pulmonary disease. $N$ Engl J Med. 2000;343(26):1902-1909.

41. Burge PS, Calverley PM, Jones PW, Spencer S, Anderson JA, Maslen TK. Randomised, double blind, placebo controlled study of fluticasone propionate in patients with moderate to severe chronic obstructive pulmonary disease: the ISOLDE trial. BMJ. 2000;320(7245): 1297-1303.

42. Jones PW, Willits LR, Burge PS, Calverley PMA. Inhaled steroids in obstructive lung disease in Europe study investigators. Disease severity and the effect of fluticasone propionate on chronic obstructive pulmonary disease exacerbations. Eur Respir J. 2003;21(1):68-73.

43. Nannini LJ, Poole P, Milan SJ, Holmes R, Normansell R. Combined corticosteroid and long-acting beta ${ }_{2}$-agonist in one inhaler versus placebo for chronic obstructive pulmonary disease. Cochrane Database Syst Rev. 2013;(11):CD003794.

44. Soriano JB, Vestbo J, Pride NB, Kiri V, Maden C, Maier WC. Survival in COPD patients after regular use of fluticasone propionate and salmeterol in general practice. Eur Respir J. 2002;20(4):819-825.

45. Sin DD, Tu JV. Inhaled corticosteroids and the risk of mortality and readmission in elderly patients with chronic obstructive pulmonary disease. Am J Respir Crit Care Med. 2001;164(4):580-584.

46. Iannella $\mathrm{H}$, Luna $\mathrm{C}$, Waterer $\mathrm{G}$. Inhaled corticosteroids and the increased risk of pneumonia: what's new? A 2015 updated review. Ther Adv Respir Dis. 2016;10(3):235-255.

47. Ferguson GT, Tashkin DP, Skärby T, et al. Effect of budesonide/ formoterol pressurized metered-dose inhaler on exacerbations versus formoterol in chronic obstructive pulmonary disease: the 6-month, randomized RISE (Revealing the Impact of Symbicort in reducing Exacerbations in COPD) study. Respir Med. 2017;132:31-41.

48. Miravitlles M, Soler-Cataluña JJ, Calle M, et al. Spanish COPD Guidelines (GesEPOC) 2017. Pharmacological treatment of stable chronic obstructive pulmonary disease. Arch Bronconeumol (English Ed). 2017; 53(6):324-335.

49. Postma DS, Rabe KF. The asthma-COPD overlap syndrome. $N$ Engl J Med. 2015;373(13):1241-1249.

50. Gershon AS, Campitelli MA, Croxford R, et al. Combination longacting $\beta$-agonists and inhaled corticosteroids compared with long-acting $\beta$-agonists alone in older adults with chronic obstructive pulmonary disease. JAMA. 2014;312(11):1114-1121.

51. Bafadhel M, Pavord ID, Russell REK. Eosinophils in COPD: just another biomarker? Lancet Respir Med. 2017;5(9):747-759.

52. Chapman KR, Hurst JR, Frent SM, et al. Long-term triple therapy de-escalation to indacaterol/glycopyrronium in patients with chronic obstructive pulmonary disease (SUNSET): a randomized, double-blind, triple-dummy clinical trial. Am J Respir Crit Care Med. 2018;198(3): 329-339.

53. Calverley PMA, Tetzlaff K, Vogelmeier C, et al. Eosinophilia, frequent exacerbations, and steroid response in chronic obstructive pulmonary disease. Am J Respir Crit Care Med. 2017;196(9):1219-1221. 
54. Rabe KF, Beghé B, Fabbri LM. Peripheral eosinophil count as a biomarker for the management of COPD: not there yet. Eur Respir J. 2017;50(5):1702165.

55. Hartjes FJ, Vonk JM, Faiz A, et al. Predictive value of eosinophils and neutrophils on clinical effects of ICS in COPD. Respirology. 2018; 23(11):1023-1031.

56. Pavord ID, Lettis S, Anzueto A, Barnes N. Blood eosinophil count and pneumonia risk in patients with chronic obstructive pulmonary disease: a patient-level meta-analysis. Lancet Respir Med. 2016;4(9):731-741.

57. Pavord ID, Chanez P, Criner GJ, et al. Mepolizumab for eosinophilic chronic obstructive pulmonary disease. $N$ Engl J Med. 2017;377(17): 1613-1629.

58. Global Initiative for Chronic Obstructive Lung Disease. Global strategy for the diagnosis, management, and prevention of chronic obstructive pulmonary disease. Available from: www.goldcopd.org. Published 2017. Accessed December 21, 2016.

59. Singh D, Brooks J, Hagan G, Cahn A, O'Connor BJ. Superiority of "triple" therapy with salmeterol/fluticasone propionate and tiotropium bromide versus individual components in moderate to severe COPD. Thorax. 2008;63(7):592-598.

60. Jung KS, Park HY, Park SY, et al. Comparison of tiotropium plus fluticasone propionate/salmeterol with tiotropium in COPD: a randomized controlled study. Respir Med. 2012;106(3):382-389.

61. Hanania NA, Crater GD, Morris AN, Emmett AH, O'Dell DM, Niewoehner DE. Benefits of adding fluticasone propionate/salmeterol to tiotropium in moderate to severe COPD. Respir Med. 2012;106(1): 91-101.

62. Frith PA, Thompson PJ, Ratnavadivel R, et al. Glycopyrronium oncedaily significantly improves lung function and health status when combined with salmeterol/fluticasone in patients with COPD: the GLISTEN study, a randomised controlled trial. Thorax. 2015;70(6):519-527.

63. Siler TM, Kerwin E, Singletary K, Brooks J, Church A. Efficacy and safety of umeclidinium added to fluticasone propionate/salmeterol in patients with COPD: results of two randomized, double-blind studies. COPD. 2016;13(1):1-10.

64. Aaron SD, Vandemheen KL, Fergusson D, et al. Tiotropium in combination with placebo, salmeterol, or fluticasone-salmeterol for treatment of chronic obstructive pulmonary disease: a randomized trial. Ann Intern Med. 2007;146(8):545-555.

65. Welte T, Miravitlles M, Hernandez P, et al. Efficacy and tolerability of budesonide/formoterol added to tiotropium in patients with chronic obstructive pulmonary disease. Am J Respir Crit Care Med. 2009;180(8): 741-750.

66. Lee SD, Xie CM, Yunus F, et al. Efficacy and tolerability of budesonide/ formoterol added to tiotropium compared with tiotropium alone in patients with severe or very severe COPD: a randomized, multicentre study in East Asia. Respirology. 2016;21(1):119-127.

67. Siler TM, Kerwin E, Tombs L, Fahy WA, Naya I. Triple therapy of umeclidinium + inhaled corticosteroids/long-acting beta 2 agonists for patients with COPD: pooled results of randomized placebo-controlled trials. Pulm Ther. 2016;2(1):43-58.

68. Short PM, Williamson PA, Elder DHJ, Lipworth SIW, Schembri S, Lipworth BJ. The impact of tiotropium on mortality and exacerbations when added to inhaled corticosteroids and long-acting $\beta$-agonist therapy in COPD. Chest. 2012;141(1):81-86.
69. Magnussen H, Disse B, Rodriguez-Roisin R, et al. Withdrawal of inhaled glucocorticoids and exacerbations of COPD. $N$ Engl J Med. 2014; 371(14):1285-1294.

70. Brusselle G, Price D, Gruffydd-Jones K, et al. The inevitable drift to triple therapy in COPD: an analysis of prescribing pathways in the UK. Int J Chron Obstruct Pulmon Dis. 2015;10(1):2207-2217.

71. Simeone JC, Luthra R, Kaila S, et al. Initiation of triple therapy maintenance treatment among patients with COPD in the US. Int $J$ Chron Obstruct Pulmon Dis. 2017;12:73-83.

72. Miyazaki M, Nakamura $\mathrm{H}$, Takahashi S, et al. The reasons for triple therapy in stable COPD patients in Japanese clinical practice. Int $J$ Chron Obstruct Pulmon Dis. 2015;10:1053-1059.

73. Martinez FJ, Rabe KF, Calverley PMA, et al. Determinants of response to roflumilast in severe COPD: pooled analysis of two randomized trials. Am J Respir Crit Care Med. 2018;198(10):1268-1278.

74. Singh D, Papi A, Vezzoli S, et al. CHF5993 pMDI (extrafine beclometasone dipropionate:BDP, formoterol fumarate:FF, glycopyrronium bromide:GB) reduces clinically important deteriorations (CID) in COPD: post-hoc analysis of TRILOGY study. Eur Respir J. 2017; 50(Suppl 61):PA533.

75. Singh D, Fabbri L, Papi A, et al. Extrafine triple therapy reduces exacerbations in GOLD B COPD patients: post-hoc analysis of TRILOGY and TRINITY. Eur Respir J. 2017;50(Suppl 61):OA2898.

76. Singh D, Papi A, Vezzoli S, et al. Effect of CHF5993 pMDI (extrafine beclometasone dipropionate:BDP, formoterol fumarate:FF, glycopyrronium bromide: GB) on clinically important deteriorations (CID) in COPD: post-hoc analysis of TRINITY study. Eur Respir J. 2017; 50(Suppl 61):PA3949.

77. Scuri M, Singh D, Fabbri LM, et al. Single inhaler extrafine triple therapy reduces clinically important deterioration (CID) in COPD compared to indacaterol/glycopyrronium: post-hoc analysis of the TRIBUTE study. Am J Respir Crit Care Med. 2018;197:A1013.

78. Scuri M, Singh D, Fabbri LM, et al. Single inhaler extrafine triple therapy improves clinical outcomes in GOLD B COPD patients: post-hoc analysis of the TRIBUTE study. Am J Respir Crit Care Med. 2018;197:A3041.

79. Scuri M, Singh D, Fabbri LM, et al. Risk of pneumonia and exacerbations with single inhaler extrafine triple therapy compared to indacaterol/ glycopyrronium: post-hoc analysis of the TRIBUTE study. Am J Respir Crit Care Med. 2018;197:A3030.

80. Suissa S, Drazen JM. Making sense of triple inhaled therapy for COPD N Engl J Med. 2018;378(18):1723-1724.

81. Janson C, Stratelis G, Miller-Larsson A, Harrison TW, Larsson K. Scientific rationale for the possible inhaled corticosteroid intraclass difference in the risk of pneumonia in COPD. Int $J$ Chron Obstruct Pulmon Dis. 2017;12:3055-3064.

82. Sonnappa S, Martin R, Israel E, et al. Risk of pneumonia in obstructive lung disease: a real-life study comparing extra-fine and fine-particle inhaled corticosteroids. PLoS One. 2017;12(6):e0178112.

83. Vanfleteren L, Ullman A, Fabbri LM. Time for a longer and better life for patients with COPD. Eur Respir J. 2018;51(1):1702569.

84. Ferguson GT, Rabe KF, Martinez FJ, et al. Triple therapy with budesonide/glycopyrrolate/formoterol fumarate with co-suspension delivery technology versus dual therapies in chronic obstructive pulmonary disease (KRONOS): a double-blind, parallel-group, multicentre, phase 3 randomised controlled tr. Lancet Respir Med. 2018;6(10):747-758.

International Journal of COPD

\section{Publish your work in this journal}

The International Journal of COPD is an international, peer-reviewed journal of therapeutics and pharmacology focusing on concise rapid reporting of clinical studies and reviews in COPD. Special focus is given to the pathophysiological processes underlying the disease, intervention programs, patient focused education, and self management protocols.

This journal is indexed on PubMed Central, MedLine and CAS. The manuscript management system is completely online and includes a very quick and fair peer-review system, which is all easy to use. Visit http://www.dovepress.com/testimonials.php to read real quotes from published authors. 